\title{
EVALUASI PROGRAM PEMBERDAYAAN USAHA GARAM RAKYAT DI KECAMATAN PANGENAN, KABUPATEN CIREBON, JAWA BARAT
}

\author{
Nandang A. Deliarnoor ${ }^{1}$, Rd. Ahmad Buchari², dan Liiklai K. Felfina ${ }^{3}$ \\ Magister Kebijakan Publik, Fakultas Ilmu Sosial dan Ilmu Politik \\ Universitas Padjajaran \\ nandangalamsah@gmail.com ${ }^{1}$ \\ ahmad.buchari@unpad.ac.id²
}

\begin{abstract}
The issue of salt production in Indonesia and to fulfill the increasing demand of salt every year through salt import, is the basis of the study. To increase productivity and quality, and the welfare of salt formers, Indonesian government has intervened through enactment of People Salt Business Empowerment Program (PUGAR) in 2011. Even with implementation of the program, problems of national salt still continue, hence there is a need to evaluate the program. The title of the study is Evaluation of PUGAR Program in Pangenan Sub-district, Cirebon District, West Java.

The methodology in this study used qualitative hybrid approach, with primary data collection from direct interviews, field observation and secondary data from documents and literature on PUGAR. Evaluation of PUGAR program used evaluation goal-based and logic model, and used William Dunn's evaluation criteria of effectiveness, efficiency, responsiveness and appropriateness as evaluation tool.

The study result shows that evaluation of PUGAR program in Pangenen Sub-district, Cirebon District has been implemented in accordance to the applied standard and guidelines, but it has not met the aspect of effectiveness in its organization and forming of people salt, efficiency of Community Direct Aid (BLM) policy to help salt farmers, responsiveness in the use of technology and appropriateness to the policies on Spatial Planning of Cirebon District and on salt import, Further in-depth study on the program is still needed.
\end{abstract}

Keyword : Program Evaluation. Salt, PUGAR, Cirebon District

\subsection{Latar Belakang Penelitian}

Garam merupakan komoditas strategis yang diperlukan untuk berbagai hal baik yang digunakan untuk produksi pangan maupun produksi industri non-pangan. Garam dibedakan menjadi dua, yaitu garam konsumsi dan garam industri. Kebutuhan garam di Indonesia tiap tahun terus meningkat. Menurut data dari Kementerian Kelautan dan Perikanan, peningkatan kebutuhan garam dalam negeri meningkat rata-rata $4,3 \%$ per tahun dari 3 juta ton di tahun 2010 menjadi 3,75 juta ton di tahun 2015. Apabila dilihat dari pertumbuhan produksi garam tahun 2010 hanya sebesar 30,6 ribu ton, hal tersebut dikarenakan adanya perubahan iklim dimana musim hujan yang terjadi hampir sepanjang tahun sehingga merusak siklus produksi garam (Tempo, 2011). Akibat rendahnya produksi garam pada tahun tersebut, maka pemerintah melakukan impor garam untuk menutupi kebutuhan tersebut.

Dalam rangka meningkatkan produksi garam untuk membantu memenuhi kebutuhan garam yang semakin meningkat tersebut, pemerintah melalui Kementerian Kelautan dan Perikanan telah mencanangkan Program Pemberdayaan Usaha Garam Rakyat (PUGAR) pada tahun 2011. Program ini merupakan bagian dari pelaksanaan Program Nasional Pemberdayaan Masyarakat Mandiri Kelautan dan Perikanan atau disingkat PNPM Mandiri KP, yang merupakan bagian dari Rencana Strategis Kementerian Kelautan dan Perikanan dalam upaya mempercepat pengentasan kemiskinan, yang ditetapkan melalui Peraturan Menteri Kelautan Dan Perikanan Nomor.41 Tahun 2011 tentang Pedoman Pelaksanaan Program Nasional Pemberdayaan Masyarakat Mandiri Kelautan Dan Perikanan.

Produksi garam sejak tahun dicanangkannya program PUGAR menunjukan tren yang meningkat yaitu di tahun 2011 produksi garam mencapai sekitar 1.1 juta ton dan menjadi 2.8 juta ton di tahun 2015, dengan peningkatan rata-rata sekitar 46,7\% setiap tahunnya (Kementerian Kelautan dan Perikanan, 2015a). Peningkatan tersebut dikarenakan peningkatan dari produksi garam yang dihasilkan dari petambak garam rakyat sebesar $46,3 \%$ per tahun dan produksi dari PT Garam (Persero) sebesar 49,3\%

Sejak dicanangkan program PUGAR telah dilaksanakan di 7 provinsi dan 40 lokasi, sentra dan penyangga garam sejak tahun 2011 dan berkembang menjadi 9 provinsi dan 43 lokasi, sentra dan penyangga 
garam pada tahun 2014. Lahan potensial produksi garam tertinggi ada di pulau Jawa dan Madura yaitu di Kabupaten Cirebon, Indramayu, Sumenep, Pati dan Sampang, masing-masing memiliki pangsa sebesar $12,6 \% ; 12,4 \% ; 11,7 \% ; 11,5 \%$ dan $10,3 \%$ dari produksi garam tahun 2014 (Ardiyanti, 2016).

Pelaksanaan program PUGAR di Kabupaten Cirebon pertama kali ditetapkan di Kecamatan Pangenan pada tahun 2011, terutama di 5 desa yang terpilih menjadi lokasi sasaran program PUGAR yaitu di Desa Bendungan, Rawaurip, Pengarengan, Pangenan dan Ender. Penetapan Kecamatan Pangenan sebagai daerah potensial bagi program PUGAR yaitu dengan kriteria lahan potensial untuk usaha garam rakyat, lokasi merupakan wilayah pesisir dan mempunyai aksesibilitas mudah dijangkau.

Kendatipun daerah ini sangat potensial, namun terdapat permasalahan krusial yang terdapat di daerah ini yaitu, sebagian dari lahannya kini telah beralih fungsi. Pada tahun 2015, telah dibangun Pembangkit Listrik Tenaga Uap I (PLTU I) di Desa Pengarengan, Kecamatan Pangenan, dan akan dibangun PLTU II di Kecamatan Astanajapura dan PLTU III di Kecamatan Mundu (RadarCirebon.com, 2016). Selain lahan yang beralih fungsi, tiap tahun lahan tambak di Kabupaten Cirebon berkurang karena abrasi laut (Liputan6.com, 2016). Struktur tanah yang berlumpur dan air laut yang tercemar, mengakibatkan produksi garam di daerah ini berwarna kusam dan berkualitas rendah.

Dalam upaya meningkatkan produktivitas dan kualitas garam rakyat, serta kesejahteraan petambak dan pelaku usaha garam rakyat, kebijakan yang diambil pemerintah melalui program PUGAR adalah dengan kelembaggan kelompok usaha garam rakyat dan pemberian Bantuan Langsung Masyarakat guna mengembangkan usaha garam rakyat, serta penerapan Teknologi Ulir Filter (TUF) dan pemberian Geoisolator/geomembrane untuk meningkatkan kualitas garam yang dihasilkan. Kebijakan pemerintah melalui program PUGAR hingga kini ternyata belum mampu memecahkan permasalahan pergaraman dalam negeri.

Hal tersebut dikarenakan hingga kini impor garam masih dilakukan pemerintah untuk menutupi kebutuhan garam dalam negeri, terutama untuk garam industri. Permasalahan lainnya adalah harga garam yang rendah di tingkat petani yaitu normalnya berkisar antara Rp.500 Rp.550/kg dan bahkan mencapai Rp.250/kg apabila panen raya. Sebenarnya untuk harga, pemerintah sudah memiliki standar harga untuk KP1, yaitu Rp 750/kg dan KP2 harganya Rp 550/kg (Peraturan Direktur Jenderal Perdagangan Luar Negeri No.02/DAGLU/PER/5/2011 tentang Penetapan Harga Penjualan Garam di Tingkat Petani Garam). Harga dibawah standar tersebut, pada umumnya karena harga sudah dipatok oleh pengepul/tengkulak, dimana hingga kini sistem distribusi dan pemasaran garam rakyat masih melalui perantara (pengepul/tengkulak).
Permasalahan lainnya adalah belum berfungsinya koperasi dalam memfasilitasi pengolahan dan akses pemasaran garam dengan dunia usaha; memfasilitasi akses permodalan bagi KUGAR; dan membantu KUGAR untuk kegiatan penyimpanan garam. Untuk mengetahui mengapa hingga kini permasalahan garam masih belum dapat diselesaikan meskipun program PUGAR sudah berjalan dari tahun 2011.

\subsection{Rumusan Masalah}

Dari uraian yang telah disampaikan pada latar belakang di atas, maka rumusan masalah dalam penelitian ini adalah:

"Mengapa Program Pemberdayaan Usaha Garam Rakyat (PUGAR) di Kecamatan Pangenan, Kabupaten Cirebon belum berhasil?”

\section{Tinjauan Pustaka}

2.1, Model Evaluasi:

a. Evaluasi Model Goal-based adalah pendekatan yang berkonsentrasi pada suatu goal proyek sebagai evaluasi preordinate, yaitu dengan melihat sejauh mana tingkat kesesuaian outcome dengan maksud dari suatu proyek/program dan bila terdapat ketidaksesuain disebut sebagai perbedaan, atau tak tercapai (Stake dalam Evers, 1980:6).

b. Model Logic adalah "....a map that graphically illustrates how your program activities will lead to the expected short-term- and long-termoutcomes." (terjemahan bebasnya: ...merupakan sebuah peta yang secara grafik mengilustrasikan bagaimana kegiatan program mengarah pada capaian jangka pendek - dan jangka panjang- outcome (Baker et al. 2000:23)

2.2. Kriteria Evaluasi Kebijakan adalah sebagai toluk ukur atau indikator dari evaluasi kebijakan dan program dengan melihat keberhasilannya dari perspektif seperti efektivitas, efisiensi, kecutupan, perataan, responsivitas dan ketepatan (Dunn, 2004:610),

2.3. Program Pemberdayaan Usaha Garam Rakyat (PUGAR)

Program Pemberdayaan Usaha Garam Rakyat (PUGAR) merupakan Program Nasional Pemberdayaan Masyarakat Mandiri Kelautan dan Perikanan (PNPM Mandiri-KP) yang diperuntukkan bagi peningkatan kesempatan kerja dan kesejahteraan petani tambak garam rakyat dan pelaku usaha garam rakyat lainnya dalam upaya mendukung swasembada garam nasional, baik garam konsumsi maupun garam industri dengan prinsip bottom-up.

\section{Metodologi}

Metodologi dalam penelitian ini menggunakan metode kualiitatif, yang disajikan dalam bentuk hybrid 
dengan data diperoleh dari data primer (wawancara langsung dengan informan kunci, dokumentasi, observasi langsung di lapangan) dan data sekunder (laporan akhir pelaksanaan program PUGAR di Kabupaten Cirebon, Jawa Barat, dan dokumen terkait lainnya.

\section{Kondisi Geografis dan Demografis Kecamatan Pangenan, Kabupaten Cirebon}

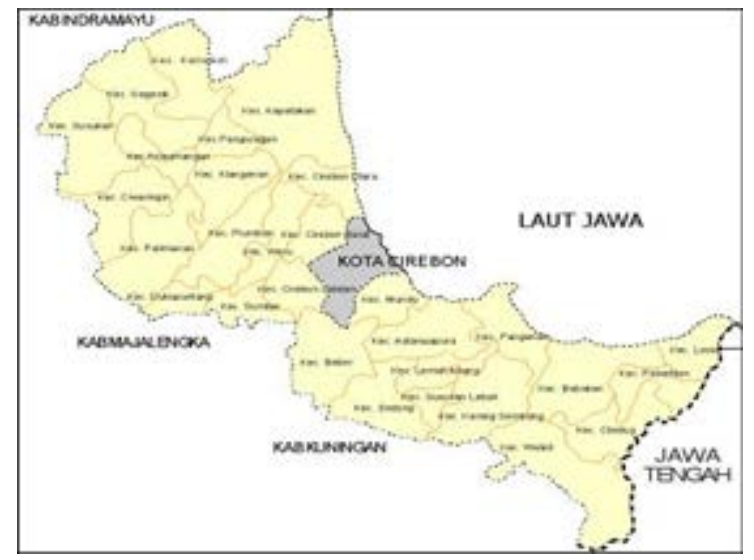

Sumber: Kabar-Cirebon.com, 2017

\section{Hasil dan Pembahasan}

\subsection{Evaluasi Model Goal-based dan Logic}

Kabupaten Cirebon yang terletak di bagian timur Provinsi Jawa Barat memiliki luas wilayah sebesar 990,36 km2. Batas wilayah administrative Kabupaten Cirebon di sebelah utara, berbatasan dengan Kabupaten Indramayu; di sebelah timur, berbatasan dengan Kota Cirebon dan Kabupaten Brebes; sedangkan di sebelah selatan, berbatasan dengan Kabupaten Kuningan, dan di sebelah barat, berbatasan dengan Kabupaten Majalengka.

Di Kabupaten Cirebon terdapat sebanyak 40 kecamatan dengan 412 desa dan 12 kelurahan, dan 8 diantaranya berada di daerah pantai laut Jawa, yaitu Kecamatan Losari, Gebang, Pangenan, Astanapura, Mundu, Gunungjati, Suranenggala dan Kapetakan. Wilayah Kecamatan Pangenan secara administratif berbatasan di sebelah utara dengan Laut Jawa, sedangkan di sebelah barat dengan Kecamatan Astanajapura, dan di sebelah selatan dengan Kecamatan Karangsembung, serta di sebelah timur berbatasan dengan Kecamatan Gebang. Kecamatan ini memiliki luas wilayah sebesar 3.046,01 ha dan memiliki 9 desa yaitu: Desa Astanamukti, Pengarengan, Rawa Urip, Bendungan, Pangenan, Ender, Gertakmoyan, Beringin, dan Japura Lor. Jumlah penduduk Kecamatan Pangenan menurut data tahun 2009 sebanyak 41.512 jiwa (Dinas Kelautan dan Perikanan Kabupaten Cirebon, 2011). 
Kerangka Kerja Model Logic - PUGAR 2011-2015

\begin{tabular}{|c|c|c|c|}
\hline $\begin{array}{l}\text { Komponen } \\
\text { Input }\end{array}$ & $\begin{array}{c}\text { Komponen } \\
\text { Kegiatan }\end{array}$ & Output & Outcome \\
\hline $\begin{array}{l}\text { - SDM } \\
\text { - Tenaga Pendamping } \\
\text {--6 org (2011-2015) } \\
\text { - Konsultan (2011-2013) } \\
\text { - Tim Teknis (OPD Kab } \\
\text { Cirebon, 2011-2015) } \\
\text { - Dana } \\
\text { - Total dana BLM Rp. } \\
\text { 19.3 M (2011-2014) } \\
\text { - Bantuan sarana } \\
\text { prasana produksi } \\
\text { (2015) }\end{array}$ & $\begin{array}{l}\text { - Pembentukan } \\
\text { Tenaga } \\
\text { Pendamping, } \\
\text { - Pembentukan } \\
\text { KUGAR, } \\
\text { - Sosialisasi, } \\
\text { penyuluhan } \\
\text { (pemberdayaan } \\
\text { ) \& pendamping } \\
\text { - Penyaluran } \\
\text { BLM, dan } \\
\text { - Monitoring dan } \\
\text { evaluasi serta } \\
\text { pelaporan }\end{array}$ & $\begin{array}{l}\text { - Terbentuk dan } \\
\text { terfasilitasi } \\
\text { KUGAR:: } \\
\text { - } 2011-110 \\
\text { - } 2012-371 \\
\text { - } 2013-397 \\
\text { - } 2014-687 \\
\text { - } 2015-81 \\
\text { - Total } 1625 \\
\text { KUGAR } \\
\text { - Tersalurkanny } \\
\text { a BLM ke } 1626 \\
\text { KUGAR } \\
\text { dengan total } \\
\text { BLM sebesar } \\
19.3 \text { Milyar dan } \\
\text { bantuan } \\
\text { sarana } \\
\text { prasarana } \\
\text { produksi }\end{array}$ & $\begin{array}{l}\text { - Meningkatkan Produksi } \\
\text { Garam } \\
\text { - } 2011=68,9 \text { ribu ton } \\
\text { - } 2012-150,0 \text { ribu ton } \\
\text { - } 2013-12,7 \text { ribu ton } \\
\text { - } 2014-107,9 \text { ribu ton } \\
\text { - } 2015=69,3 \text { ribu ton } \\
\text { - Meningkatkan } \\
\text { pendapatan KUGAR } \\
\text { Belum ada data tentang } \\
\text { peningkatan } \\
\text { pendapatan KUGAR } \\
\text { - Penumbuhan wirausaha } \\
\text { pergaraman } \\
\text { - Usaha garam rakyat di } \\
\text { Kecamatan Pangenan } \\
\text { berupa industry } \\
\text { rumahan yang masih } \\
\text { sedikit jumlahnya dan } \\
\text { sebagian besar berada } \\
\text { di Desa Bendungan. } \\
\text { Hal tersebut belum } \\
\text { menggambarkan } \\
\text { tumbuhnya wirausaha- } \\
\text { wan karena pemasaran } \\
\text { garam masih ter- } \\
\text { gantung perantara. }\end{array}$ \\
\hline
\end{tabular}

Sumber: Data diolah peneliti dari Laporan Akhir Kegiatan PUGAR, Dinas Kelautan dan Perikanan Kabupaten Cirebon, 2011-2015

Dari kerangka kerja model logic, pada tabel 1.1, diketahui bawah perencanaan input yaitu sumber daya yang digunakan terbatas terutama SDM dimana sumber daya dalam hal ini Tenaga Pendamping yang memiliki peran mendampingi KUGAR dalam kelembagaan dan pengembangan produksi usaha garam rakyat serta pengawasan, terbatas jumlahnya dengan rasio 1:69 KUGAR atau 1 Tenaga Pendamping mendapingi 69 kelompok dengan anggota lebih dari 600 orang. Hasil dari input dan kegiatan yaitu output dengan indikator keberhasilan berupa terbentuknya dan terfailitasinya KUGAR dan penyaluran BLM.

Dilihat dari terbentuknya KUGAR, output ini berhasil namun dari petambak belum semuanya mendapatkan kesempatan untuk terlibat dalam pelatihan peningkatan kapasitas karena selama program PUGAR dijalankan peserta yang ikut pelatihan adalah ketua kelompok. Hal ini sesuai dengan hasil wawancara peneliti dengan beberapa petambak di Desa Bendungan, Pangenan dan Rawaurip yang menyebutkan bahwa peserta yang ikut pelatihan adalah ketua kelompok. Dari indikator tersalurnya BLM, meskipun BLM telah disalurkan sesuai ketentuan yang telah ditetapkan, namun pemanfaatan bantuan ini tidak tepat karena proses administrasi identifikasi, seleksi dan penetapan KUGAR yang panjang menghambat pencairan BLM lebih awal, sehingga BLM yang diperoleh oleh petambak waktunya sudah memasuki musim panen, sehingga BLM ini tidak membantu petambak dalam usaha garam rakyat mereka.
Outcome dari program PUGAR yang dijalankan yaitu masih fluktuatif karena produksi masih tergantung faktor cuaca, dimana bila musim kemarau panjang maka produksi garam akan tinggi, dan sebaliknya menjadi rendah bila musim kemarau pendek. Indikator outcome meningkatnya pendapatan petambak tergantung dari luas lahan yang dimiliki petambak, dan banyak dari petambak bukan pemilik lahan, yaitu melalui sewa atau bagi hasil. Selain itu banyak dari petambak terutama di Desa Bendungan, Pangenan dan Rawaurip memiliki profesi selain penggarap garam seperti petani di Desa Pangenan, dan di Desa Bendungan dan Rawaurip sebagai pembudidaya ikan dan udang, bahkan ada yang menjadi TKI di luar negeri, sehingga pendapatan mereka tidak bisa dihitung hanya dari garam. Sedangkan indikator outcome pertumbuhan wirausaha pergaraman, belum terlihat pertumbuhan signifikan karena jangkauan pemberdayaan yang terbatas belum menyeluruh, dan dilihat dari masih tergantungnya petambak pada peramtara dalam distribusi dan pemasaran hasil garam mereka.

Dari uraian tersebut, maka program PUGAR diketahui belum dapat mencapai outcome yang diharapkan. Belum berhasilnya kebijakan program ini dinilai dari kriteria sebagai berikut:

\subsection{Effectiveness (Efektivitas) \\ Keefektivan disini terkait dari kinerja pelaksana program dan koordinasi antar lembaga dan}


kelembagaannya. Kelembagaan disini terdiri dari kelembagaan program PUGAR dan kelembagaan KUGAR. sebagai berikut:

\section{a. Kelembagaan Program PUGAR}

Kelembagaan program PUGAR dinilai dari kinerjanya belum efektif karena belum terbentuknya koordinasi dan kerja sama dalam memcahkan persoalan pergaraman di Kabupaten Cirebon, terutama di Kecamatan Pangenan. Hal ini antara lain keterlibatan OPD dalam Tim Teknis yang program ini hanya bersifat procedural, yaitu menjalankan perannya dalam proses seleksi dan verifikasi KUGAR dan belum dalam memecahkan permasalahan pergaraman. Misalnya keterlibatan Bappeda belum dalam bentuk teraloksinya anggaran di APDN dalam menunjang kebijakan pemerintah pusat melalui program PUGAR. Hal tersebut berdampak pada masih tingginya permasalahan pergaraman yang sama ketika program PUGAR dimulai hingga program tersebut telah berjalan 5 tahun, antara lain faktor masih rendahnya sarana dan infrasktruktur daerah tambak, sulitnya akses terhadap permodalan dsb.

Selain itu, belum berfungsunya Koperasi dan/atau BUMDes dalam membantu petambak dalam mengelola dan memelihara gudang dan/atau UPG; membantu KUGAR dalam memenuhi kualitas garam; memfasilitasi pengolahan dan pemasaran garam dengan dunia usaha; dan memfasilitasi pembiayaan KUGAR b. Kelompok Usaha Garam Rakyat (KUGAR).

Kebijakan pembentukan KUGAR belum efektif karena belum memberi pengaruh pada pengembangan usaha garam rakyat sebagaimana tujuan awal dibentuknya KUGAR. Hal tersebut karena pembentukan KUGAR selama program PUGAR dilaksanakan hanya untuk penyaliran BLM, sehingga bukan atas keperluan dan keinginan petambak.

\subsection{Efficiency (Efisiensi)}

Belum efisiensinya kebijakan program PUGAR dilihat dari penggunaan sumber daya dan kegiatan yang dilakukan. Sebagaimana dinyatakan oleh Dunn (2000:430) bahwa efisiensi diartikan dalam jumlah usaha yang diperlukan untuk menghasilkan tingkat efektivitas tertentu, yang sama dengan rasionalitas ekonomi yaitu hubungan antara efektivitas dan usaha yang umumnya diukur dari ongkos moneter. Kebijakan program PUGAR dinilai belum efisien karena dilihat dari sumber daya baik anggaran dan SDM tidak menghasilkan output yang diharapkan untuk mencapai tujuan yang diinginkan. Dalam hal ini pemberian BLM yang telah dilakukan selama program PUGAR dari 20112015 tidak membantu dalam meningkatkan kualitas dan kesejahteraan petambak sehingga program ini menjadi tidak efisien.

\subsection{Responsiveness (Responsivitas)}

Responsivitas menurut Langbein dan Felbinger (2006:7) adalah: “...whether the program conforms to the preferences of voters or meets with the satisfaction of its clients” (diartikan secara bebas yaitu apakah program sesuai dengan keinginan pemilih atau memenuhi kepuasan dari kliennya). Dari pendapat tersebut apabila melihat kebijakan program PUGAR yang telah dijalankan di Kabupaten Cirebon selama ini lebih bersifat procedural yang telah ditetapkan oleh pemerintah pusat, yakni Kementerian Kelautan dan Perikanan dan belum mencerminkan yang benar-benar dibutuhkan publik dalam hal ini petambak garam rakyat di Kabupaten Cirebon. Hal tersebut karena, program ini belum mencerminkan pendapat petambak yang umumnya ingin agar pemerintah dapat menjaga harga di tingkat petani, sehingga petambak dan pelaku usaha garam rakyat tidak dirugikan.

\subsection{Appropriateness (Ketepatan)}

Belum adanya ketepatan kebijakan program PUGAR ini, karena ketepatan berhubungan dekat dengan rasionalitas substantive, yang berkenaan dengan dua atau lebih kriteria secara bersama-sama, yang merujuk pada harga dan nilai dari tujuan program dan pada kuatnya asumsi-asumsi yang melandasi tujuan tersebut (Dunn, 2000:438). Dari uraian tersebut maka ketepatan program PUGAR ini melihat dari regulasi RTRW Kabupaten Cirebon dengan regulasi impor garam dalam negeri.

a. Regulasi tentang Rencana Tata Ruang Wilayah Kabupaten Cirebon

Kebijakan program PUGAR dinilai aspek appropriateness belum memenuhi dengan merujuk pada RTRW Kabupaten Cirebon, terutama Kecamatan Pangenan. Hal tersebut bila dilihat telah dibangun Pembangkit Listrik Tenaga Uap I (PLTU I) di Desa Pengarengan, Kecamatan Pangenan pada tahanu 2015 yang lalu. Direncanakan pula bahwa kelanjutan pembangunan PLTU II di Kecamatan Astanajapura dan PLTU III di Kecamatan Mundu (RadarCirebon.com, 2016). Hal tersebut, seperti yang dikemukakan oleh Dinas Cipta Karya dan Tata Ruang (CKTR) Kabupaten Cirebon, Tatit Konitat, dikutip dari Radar Cirebon (2016), bahwa pengembangan kawasan industri diperuntukan terutama di kawasan Cirebon Timur (dari Kecamatan Mundu hingga Losari) dan menambahkan bahwa "rencana Pemerintah Kabupaten Cirebon membuat wilayah timur menjadi kawasan industri adalah untuk mengimbangi sentra industri di wilayah barat" (RadarCirebon.com, 2016).

Peruntukan wilayah Cirebon Timur sebagai kawasan industri besar, mengacu pada pasal 47 ayat 2 Perda Kabupaten Cirebon No. 17 Tahun 2011, yang berbunyi: "sebagai kawasan peruntukan industri besar seluas kurang lebih 2.000 (dua ribu) hektar meliputi: huruf (c) Kecamatan Pangenan meliputi industri manufaktur dan industri hasil tambang” dan pasal 47 ayat 4: yang berbunyi: "sebagai kawasan Industri kecil dan mikro meliputi huruf (j) Kecamatan Pangenan berupa industri garam.”

Disamping itu, menurut Perda ini Kecamatan Pangenan merupakan kawasan rawan abrasi laut, 
sebagaimana disebutkan pada pasal 35 ayat 3 (c) , yang berbunyi: "kawasan rawan abrasi seluas kurang lebih 540 ha meliputi daerah antara lain Kecamatan Pangenan. b Regulasi tentang Impor Garam

Kebijakan pemerintah untuk menutupi kebutuhan garam adalah dengan melakukan impor garam salah satunya dari Australia. Impor garam ini sebagian besar adalah garam untuk keperluan industri. Menurut Ketua Asosiasi Petani Garam Kabupaten Cirebon, Insyaf Supriyadi, bahwa "impor sudah rutin dilakukan oleh perusahaan garam sejak lima tahun terakhir, dengan jumlah antara 25 ribu-30 ribu ton per tahun" (Republika.co.id, 2016). Hal tersebut dilakukan untuk memenuhi kebutuhan garam industri di Kabupaten Cirebon, dimana ia mengatakan pula bahwa "garam yang dihasilkan petani garam di Kabupaten Cirebon, selama ini hanya bisa mencapai kualitas dua (KP2)" (Republika.co.id, 2016)..

Kebijakan impor tersebut mengacu pada Peraturan Menteri Perdagangan Nomor 125 Tahun 2015 Tentang Ketentuan Impor Garam. Kebijakan yang sekarang berlaku telah menghilangkan ketentuan penyerapan garam produksi rakyat oleh importir garam sebagaimana kebijakan sebelumnya yaitu Peraturan Menteri Perdagangan Nomor 58/M-Dag/Per/9/2012 tentang Ketentuan Impor Garam pasal 5 ayat (3) yang berbunyi:

"Penetapan jumlah alokasi impor Garam Konsumsi nasional sebagaimana dimaksud pada ayat (1) dialokasikan kepada IP Garam Konsumsi secara proporsional berdasarkan besarnya pembelian garam produksi dalam negeri."

Perbedaan ketentuan impor garam yang sekarang dan sebelumnya adalah sekarang dimonopoli oleh PT Garam yang merupakan BUMN. Namun dengan ketentuan impor garam yang tidak mengharuskan PT Garam menyerap hasil produksi lokal, dianggap merugikan petambak garam rakyat, dan tentunya tidak sesuai dengan tujuan dari program PUGAR yaitu untuk meningkatkan kualitas garam rakyat, agar dapat terpenuhinya kebutuhan dalam negeri akan garam industri.

\section{Kesimpulan}

Dari uraian tersebut, dapat disimpulkan bahwa program PUGAR di Kecamatan Pangenan Kabupaten Cirebon, meskipun telah dijalankan sesuai ketentuan yang berlaku, tetapi hanya bersifat prosedural dan belum berfungsinya organisasi penunjangnya. Program ini dinilai belum berhasil karena belum memenuhi kriteria efektivitas (effectiveness) dalam kerja sama dan koordinasi kelembagaan program PUGAR serta kelembagaan KUGAR; aspek efisiensi (Efficiency) dari kegiatan penyaluran BLM, aspek responsivitas (responsiveness) program PUGAR bukan berdasarkan kebutuhan publik yaitu petambak di daerah ini, dan apek ketepatan (appropriateness) dari .regulasi dalam memberi perlindungan bagi petambak rakyat dari gagalnya produksi bila terjadi bencana, alih fungsi lahan, impor garam dsb.

\section{Daftar Pustaka}

Dinas Kelautan dan Perikanan Kabupaten Cirebon. 2011. Laporan Akhir Pelaksanaan Program Pemberdayaan Usaha Garam Rakyat (PUGAR) Tahun Anggaran 2011. Cirebon

2012. Laporan Akhir

Pelaksanaan Program Pemberdayaan Usaha Garam Rakyat (PUGAR) Tahun Anggaran 2012. Kabupaten Cirebon

2013. Laporan Akhir Pelaksanaan Program Pemberdayaan Usaha Garam Rakyat (PUGAR) Tahun Anggaran 2013. Kabupaten Cirebon

2014. Laporan Akhir

Pelaksanaan Program Pemberdayaan Usaha Garam Rakyat (PUGAR) Tahun Anggaran 2014. Kabupaten Cirebon

.. 2015. Laporan Akhir

Pelaksanaan Program Pengembangan Usaha

Garam Rakyat (PUGAR) Tahun Anggaran 2015. Kabupaten Cirebon

Dunn, William. 2000. Pengantar Analisis Kebijakan Publik. Edisi Kedua, $\quad$ Yogyakarta: Gadjah Mada University Press.

2003. Pengantar Analisis

Kebijakan Publik. Edisi Kedua, Yogyakarta: Gadjah Mada University Press.

Evers, John W.. 1980. A Field Study of Goal-Based and Goal-Free Evaluation Techniques, Dissertations.

2645. Michegan: WMU melalui $<$ http://scholarworks.wmich.edu/dissertations/2 645> [1/12/2017]

Langbein, Laura with Claire L. Felbinger. 2006, Public program evaluation: a statistical guide. New York: M.E. Sharpe, Inc

Peraturan Menteri Kelautan dan Perikanan Republik Indonesia Nomor PER.41/MEN/2011 tentang Pedoman Pelaksanaan Program Nasional Pemberdayaan Masyarakat Mandiri Kelautan dan Perikanan Tahun 2011.

Peraturan Menteri Kelautan Dan Perikanan Republik Indonesia Nomor 2/Permen- Kp/2013 Tentang Pedoman Pelaksanaan Program Nasional Pemberdayaan Masyarakat Mandiri Kelautan Dan Perikanan.

Peraturan Menteri Perdagangan Nomor 125/MDAG/PER/23/ 2015 tentang Ketentuan Impor Garam.

Peraturan Direktur Jenderal Kelautan, Pesisir, dan PulauPulau Kecil Nomor O 08/PER-DJKP3K/2011

tentang Pedoman Teknis Pemberdayaan Usaha Garam Rakyat (PUGAR) Tahun 2011. 
Evaluasi Program Pemberdayaan Usaha Garam Rakyat Di Kecamatan Pangenan, Kabupaten Cirebon, Jawa Barat (Nandang A. Deliarnoor, Rd. Ahmad Buchari, dan Liiklai K. Felfina)

Peraturan Direktur Jenderal Kelautan, Pesisir, dan PulauPulau Kecil Nomor O5/PER-DJKP3K/2014

tentang Pedoman Teknis Pemberdayaan Usaha Garam Rakyat (PUGAR) Tahun 2014.

Peraturan Daerah Kabupaten Cirebon Nomor 17 Tahun 2011 Tentang Rencana Tata Ruang Wilayah Kabupaten Cirebon Tahun 2011-2031.

Scriven, Michael. 1981. Evaluation Thesaurus, Third Edition, California: $\quad$ Edgepress 